\title{
UMA RELAÇÃO INCÔMODA: O CASO DO FEMINISMO E DA ANTROPOLOGIA ${ }^{l}$
}

\author{
Marilyn Strathern ${ }^{2}$
}

\begin{abstract}
Resumo
Esse artigo explora alguns dos problemas - e as reações - que se colocam no diálogo entre práticas disciplinares e a teoria feminista. Foca-se na relação do(a) investigador(a) com o seu tema ou objeto, uma fonte de dissonância particularmente difícil entre a prática feminista e a prática da antropologia social. Certamente, a antropologia tem interesses paralelos aos dos estudos feministas, mas a proximidade faz com que a resistência dos antropólogos seja mais aguda. Podese afirmar que esta dissonância é na verdade produto da proximidade intelectual de feministas e antropólogos(as) - como vizinhos em conflito. Os(as) praticantes de ambas imaginam que podem derrubar paradigmas existentes, e poder-se-ia, por

${ }^{1}$ Este artigo é baseado em uma palestra dada na série Changing paradigms: The impact of feminist theory upon the world of scholarship, no Research Center for Women's Studies, em Adelaide, Austrália, julho de 1984. Agradeço a Susan Margarey pelo convite e pela hospitalidade, e por chamar minha atenção sobre a questão dos paradigmas. A palestra foi publicada no Australian Feminist Studies Journal 1(Dezembro de 1985, p. 1-25). Eu havia falado sobre temas similares no Departamento de Antropologia, na University of California, em Berkeley, e na History of Consciousness Unit, em Santa Cruz, e sou grata aos (às) colegas de ambos os lugares pelos seus comentários. A inspiração também veio do Research Group on Gender Relations, em Southwest Pacific, na Australian National University. Os(as) leitores(as) da revista irão reconhecer suas ideias, às quais sou muito grata.

Este artigo é tradução de An awkward relationship: the case of feminism and anthropology, publicado em Signs Journal of Women in Culture and Society, n. 2, vol. 12, 1987, pp.276-292. A Comissão Editorial da Revista Mediações agradece aos editores e à autora por autorizarem esta publicação. Tradução: Sávio Cavalcante e Anna Martha Rosa. Revisão de Martha Ramírez-Gálvez.

${ }^{2}$ Professora Emérita de Antropologia Social, Universidade de Cambridge. End. eletrônico: ms10026@cam.ac.uk
\end{abstract}


sua vez, esperar que a antropologia "radical" extraia sua contrapartida feminista, o que não parece ter acontecido. A resistência entre eles irá iluminar a diferença entre "feminismo" e "antropologia" como tais.

Palavras-chave: Feminismo. Antropologia. Paradigmas.

\section{AN AWKWARD RELATIONSHIP: THE CASE OF FEMINISM AND ANTHROPOLOGY}

\section{Abstract}

This article explores some of the problems - and reactions - that arise in the dialogue between disciplinary practices and feminist theory. Certainly anthropology has interests parallel to those of feminist scholarship, but the proximity makes anthropologists' resistance more poignant. That dissonance is actually a product of feminists' and anthropologists' intellectual proximity - as neighbors in tension. Practitioners of both imagine they might be overthrowing existing paradigms, and one might, in turn, expect "radical" anthropology to draw on its feminist counterpart, what does not seem to have happened. Their resistance to one another will throw light on the difference between "feminism" and "anthropology" as such.

Keywords: Feminism. Anthropology. Paradigms.

0 $s$ estudos feministas oferecem a promessa de uma base comum entre as disciplinas. Contudo, essa mesma promessa também levanta questões sobre 0 impacto das teorias feministas no mainstream do desenvolvimento das disciplinas. De fato, uma ideia - o desejo de estabelecer centros de estudos feministas autônomos - invariavelmente faz pensar em outra - o desejo de revolucionar o mainstream estabelecido - um par de proposições que encasulam a divisão ideal entre autonomia e integração que dão às teorias feministas o seu lado político. 0 fato de que estudos feministas trabalham de forma transversal à divisão das disciplinas significa que eles não podem ser paralelos às mesmas, o que é incômodo em relação à ideia de que visões feministas podem modificar o trabalho em qualquer disciplina, por exemplo, na antropologia. Para que seu impacto seja registrado nas teorizações dominantes, os estudos feministas teriam que ser constituídos como uma "disciplina" irmã isomórfica, da qual ideias e 
conceitos poderiam ser tirados. Qualquer conceituação de relacionamento entre feminismo e antropologia deve considerar essa dificuldade.

Muita da literatura sobre os fracassos dos estudos feministas em mudar as disciplinas assume o isomorfismo dos estudos feministas e das disciplinas tradicionais, segundo o qual isso é normalmente concebido em termos da imensa tarefa da mudança de paradigma. A ideia de que paradigmas podem ser mudados sugere duas coisas ao mesmo tempo. As suposições subjacentes, que constituem 0 viés disciplinar em seu estado não modificado, são expostas e, ao mesmo tempo, são deslocadas com um marco de consciência teórica que desafia marcos teóricos existentes. Assim, abrem-se premissas fundamentais para este intento. Contudo, essa ideia de mudança de paradigma, tão bem quista às nossas representações acerca do que fazemos, acaba sendo uma descrição inadequada de nossa prática. Eu tentarei mostrar por quê.

As disciplinas são distintas tanto em seus objetos de estudo como em suas práticas. Os estudos feministas examinam novos assuntos que podem ser oferecidos às diferentes disciplinas: "colocando as mulheres no centro como objeto de pesquisa e como agente ativo no acúmulo de conhecimento" (STACEY \& THORNE, 1985) 3 . 0 que há, então, em relação às diferentes práticas? As práticas são constituídas por marcos teóricos, por conceitos dados e pressupostos, e também pelo tipo de relacionamento que o investigador estabelece com o próprio tema ou objeto. Esse artigo explora alguns dos problemas - e as reações - que se colocam no diálogo entre as práticas disciplinares e a teoria feminista. Foca-se na relação do(a) investigador(a) com o seu tema ou objeto, uma fonte de dissonância particularmente difícil entre a prática feminista e a prática da disciplina que conheço melhor, a antropologia social.

Talvez seja irônico destacar a dissonância entre feminismo e antropologia, já que a antropologia é por vezes destacada como tendo sido muito afetada pelo pensamento feminista. Certamente, a antropologia tem interesses paralelos aos dos estudos feministas, mas a proximidade faz com que a resistência dos antropólogos seja mais aguda. De fato, isso pode bem ser, como um(a) dos(as) leitores de Sings assinalou, que a dissonância é na verdade produto da proximidade intelectual de feministas e antropólogos(as) - que eles são, assim como o(a) leitor(a) sugeriu, vizinhos em conflito, vizinhos cujas similaridades provocam entre eles escárnio mútuo. Quero aprofundar este ponto considerando a dissonância entre ramos

${ }^{3}$ Sou grata a Barrie Thorne, de quem este artigo muito se beneficiou.

UMA RELAÇÃO INCÔMODA: O CASO DO FEMINISMO... 
específicos do feminismo e da teorização antropológica, que superficialmente parecem compatíveis uma à outra. Ao invés de olhar para áreas bem estabelecidas da antropologia, eu contemplo uma abordagem inovadora que divide interesses comuns com o feminismo radical. Os(as) praticantes de ambas imaginam que podem derrubar paradigmas existentes, e poder-se-ia, por sua vez, esperar que a antropologia "radical" extraia sua contrapartida feminista. Isso não parece ter acontecido. A resistência entre eles irá iluminar a diferença entre "feminismo" e "antropologia" como tais.

\section{ANTROPOLOGIA: BEM OU MAL SUCEDIDA?}

A afinidade entre o feminismo e o pensamento antropológico é central nas considerações de Judith Stacey e Barrie Thorne sobre a ausência da revolução feminista na sociologia. A antropologia, elas afirmam, se junta à história e à literatura como os campos nos quais surgiram os conceitos feministas mais significativos. Os expressivos ganhos da antropologia podem ser atribuídos à "significativa marca feminista nos pavimentos da antropologia desde os primeiros dias da disciplina" à centralidade do parentesco e do gênero na análise da antropologia tradicional, e à perspectiva holística que aceita o gênero como um princípio de fundo da organização social (STACEY \& THORNE, 1985, p. 303)4 .

De várias formas, as ideias geradas pela pesquisa feminista têm recebido respostas imediatas no mainstream da antropologia social que faz descrições de outras sociedades. Ninguém pode continuar falando de forma inconsciente sobre a posição da mulher. Não é mais possível supor que mulheres devem ser avaliadas pelo status que têm em relação aos outros ou relegadas a um capítulo que trate sobre o casamento e a família. 0 estudo de gênero tem se tornado um campo por direito próprio. As áreas mais importantes da antropologia foram rapidamente colonizadas por tais ideias durante 0 grande crescimento do interesse no feminismo nos anos de 1970, criando uma subdisciplina: a antropologia feminista. As primeiras perguntas formuladas pela antropologia feminista - Qual é o lugar da ideologia na representação coletiva? Como surgem os sistemas de desigualdade? Categorias analíticas tais como "doméstico" e "político" são úteis? E, como são constituídas noções de pessoa [personhood]? - permanecem à frente

\footnotetext{
${ }^{4}$ Ver também MacCormack (1981). Shapiro (1983, p. 112), contudo, inclui a antropologia na sua crítica severa das ciências sociais, que "ainda tem de chegar a um acordo do gênero como um fato social".
} 
de suas preocupações. Além do mais, a disciplina fornece materiais para parte do empreendimento feminista, a saber, a minuciosa pesquisa acerca dos construtos ocidentais. Antropólogos têm investigado os idiomas biologistas de Ocidente; têm enfatizado que o que acontece com as mulheres não pode ser compreendido a não ser que observemos o que acontece aos homens e às mulheres, e o que acontece neste domínio não pode ser compreendido sem prestar a atenção a todo 0 sistema social; e continua a fornecer vislumbres de outros mundos, em diferentes formas de opressão e de liberdade. A antropologia proporciona uma série de dados interculturais que, para tomar emprestada uma frase, são bons para pensar.

Adisciplina, assim, parece oferecer uma posição sem paralelo apartirda qual se investigam as suposições ocidentais, alargando a extensão do empreendimento feminista ao nos lembrar das condições sob as quais as mulheres vivem em outros lugares. Todavia, no começo dos anos de 1970, interesses específicos feministas entraram na antropologia na forma de contundentes ataques ao viés masculino da disciplina. Esse foi um sinal claro que antropólogos(as) não podiam se dar ao luxo de serem complacentes. Ter dado simplesmente um "espaço" para as mulheres, em algum lugar de suas considerações, não era suficiente; eles poderiam muito bem estar reproduzindo as avaliações masculinas das mulheres nas sociedades que estudam. Essa crítica feminista deste viés rapidamente achou seu alvo. Afinal, as feministas estavam exigindo o tipo de questões sobre ideologias e modelos que os(as) antropólogos(as) reconheciam. Em suma, elas deram uma excelente recomendação antropológica 5 .

Stacey e Thorne perceberam tais inovações na antropologia através da fórmula de mudança de paradigma. Para elas, os ganhos feministas na antropologia mudaram paradigmas em dois sentidos: os marcos conceituais existentes foram desafiados e a transformação foi aceita por outros na disciplina. Deste modo, "de todas as disciplinas, a antropologia feminista foi a mais exitosa em ambas dessas dimensões” (STACEY \& THORNE, 1985, p. 302).

A antropologia é similarmente destacada, embora de forma menos otimista, na coletânea de ensaios de Elizabeth Langland e Walter Gove (1983) sobre as perspectivas feministas na academia. Comparando a situação dessas questões em diversas disciplinas, eles concluem que antropólogos têm sido sensíveis, há muito

\footnotetext{
${ }^{5}$ Ver Atkinson (1982, p. 238). Ironicamente, o texto de Ardener (1972) sobre a questão das mulheres foi escrito para elucidar certos traços do modelo construído e, retrospectivamente, tornou-se uma contribuição à literatura feminista.
} 
tempo, às diferenças entre os comportamentos masculinos e femininos, mas eles param por aí. Enquanto Stacey e Thorne vêem a antropologia ${ }^{6}$ como a realização de uma dupla mudança de paradigma, a reflexão mais pessimista de Langland e Gove considera que a maior mudança ainda está por vir. Entretanto, esses autores tomam igualmente a transformação dos marcos de referência como critério de sucesso.

Langland e Gove falam sobre a resistência documentada em suas coleções: os(as) estudiosos(as) concordam que enquanto "a perspectiva feminista começou a afetar a forma do queéconhecido - e conhecível-em suas respectivas disciplinas, talvez o mais urgente a ser notado em cada ensaio é o fracasso doswomen's studies em modificar o currículo das faculdades e universidades. Textos e mais textos concluem que, enquanto o poder potencial para transformar a disciplina é grande, os estudos das mulheres ainda não tem desencadeado este poder" (LANGLAND \& GOVE, 1983, p. 2). Eles reproduzem uma visão geral dos estudos das mulheres que se refere à "resistência massiva contra a qual as estudiosas feministas lutam" (BOXER, 1982, p. 260). Langland e Gove se perguntam sobre a causa do fracasso. A resposta por eles fornecida se dá em termos de um modelo de paradigma (embora não seja a frase que eles usam): "Estudos de mulheres tiveram um impacto tão pequeno nos corpos tradicionais de conhecimento porque desafiam crenças profundamente arraigadas, frequentemente sacralizadas (...), desafiam o jogo de interesses particulares; desarraigam perspectivas que são familiares e, por conta da familiaridade, [são] confortáveis (...) [Por causa disso] os estudos sobre as mulheres não são um mero conhecimento adicional a ser acrescentado ao currículo. Ao invés, é um corpo de conhecimento de perspectiva transformadora e deveria, portanto, transformar o currículo existente internamente e revisar noções recebidas do que constitui uma perspectiva "objetiva" ou "normativa" (LANGLAND \& GOVE, 1983, p. 3-4). Em outras palavras, as análises feministas não têm influenciado substancialmente os currículos tradicionais porque tais análises desafiam os marcos de referência disciplinares fundamentais.

Na medida em que o impacto do pensamento feminista na antropologia está em questão, onde se colocaria a resistência? Pode-se, de fato, ver isto em termos de desafio e contradesafio sobre paradigmas?

\footnotetext{
${ }^{6}$ Refiro-me à antropologia social/cultural. Uma argumentação moderada para a antropologia física é colocada por Longino \& Doell (1983, p. 226).
} 
A antropologia social é, de várias formas, uma disciplina aberta. Enfrentada contra uma multiplicidade de sistemas culturais e sociais, seus profissionais tendem a se agarrar a um jogo de ferramentas que, segundo a expressão de James Clifford (1983), contém construções tais que podem adquirir utilidade analítica. As especializações proliferam - etnografia regional, econômica e política, teoria legal - assim como os marcos teóricos - marxismo, estruturalismo, antropologia simbólica. Essa tolerância deu espaço aos estudos de gênero e às ideias feministas. Contudo, um ambiente de tolerância também reduziu os estudos feministas a apenas outra abordagem, um caminho entre vários em relação aos dados. Conseqüentemente, o interesse declarado em colocar as mulheres de volta no mapa encoraja o confinamento teórico. Se os estudos feministas são vistos como o estudo sobre mulheres ou gênero, seu objeto pode ser tomado como algo menos que a "sociedade". A antropologia feminista é, desta maneira, tratada como uma especialidade que pode ser absorvida sem desafiar todo o conjunto.

Dentro da antropologia, poucos nomes são associados a uma posição exclusivamente feminista. Ou melhor, a antropologia feminista está atada a uma categoria geral: a "mulheres", que compreende tanto suas praticantes, quanto seu objeto ${ }^{7}$. Certamente, a intenção de muitas estudiosas feministas é recolocar as mulheres na visão geral, mas é lamentável que suas preocupações possam ser concretizadas desta forma. No lugar em que as antropólogas feministas se vêem a si mesmas como tomando parte da disciplina como um todo, elas vão de encontro com a tendência de separar análises de gênero ou estudos sobre mulheres do resto da antropologia. Talvez, como argumentariam Langland e Gove, esta é uma reação à ameaça. A antropologia inspirada pelo feminismo que levanta questões sobre o viés masculino pode ser considerada como um desafio aos fundamentos da disciplina, com sua ênfase teórica nas estruturas de grupo, nos sistemas de autoridade, nas regras e normas, e com suas suposições sobre a descrição de sistemas totais. Ironicamente, entretanto, onde esses conceitos estiveram de maneira mais poderosa sob um exame minucioso - e "grupos", "regras", e "normas" têm apenas sobrevivido na última década - foi uma resposta às criticas internas que tiveram pouco a ver com a teoria feminista. Enquanto isso, a antropologia social ainda continua a se reconhecer como o estudo do comportamento social ou da sociedade em termos de sistema e de representação coletiva. Se isto constitui um paradigma, então está amplamente intacto.

${ }^{7}$ Ver Shapiro (1979). 
Isto é, de fato, um processo de desafio e contradesafio? A teoria feminista apresenta profunda ameaça ao núcleo dos paradigmas? E tem sido a ameaça engenhosamente desviada pelo resto da população antropológica, supondo-a apenas como "sobre as mulheres"? Ambas as ideias do desafio e contradesafio, e a outra face da antropologia, sua abertura às ideias feministas, convidam a pensar em termos de paradigmas. De fato, Stacey e Thorne caracterizam os campos nos que o feminismo tem tido maior avanço como aqueles com "forte tradições de entendimento interpretativo", isto é, aqueles que são reflexivos e autocríticos (STACEY \& THORNE, 1985, p. 309). Aqui a conclusão pareceria ser de que aquelas disciplinas mais cientes das bases paradigmáticas das quais procedem serão mais abertas a mudanças de paradigma. Esse argumento, entretanto, contem uma falha interessante.

A falha se mostra visível pela invocação do trabalho de Thomas Kuhn sobre os paradigmas na teoria cientifica. Sem tal advertência, pode-se remeter ao senso comum do entendimento de paradigmas como um "marco de referências conceituais básico e que orienta suposições de um corpo de conhecimento" (STACEY \& THORNE, 1985, p. 302; KUHN, 1970) ${ }^{8}$. Contudo, uma característica significativa do paradigma kuhniano é que os cientistas que ele estudou passaram a conhecer a troca de paradigma apenas depois do fato. A questão toda é que eles não anseiam a mudança de paradigmas - eles visam explicar as coisas por aquilo que eles conhecem. As ideias gêmeas sobre paradigma e a possibilidade de alteração deles permanecem fortes. Essas ideias pertencem à maneira inovadora de os estudiosos se representarem a si mesmos. Eles são parte da forma do que eles falam sobre o que fazem. A imagem da perspectiva de transformação pertence à retórica do radicalismo - e necessita explicação como parte desta retórica9 .

\section{A Retórica dA MUdANÇA DE PARADIGMA}

A palavra paradigma entra no vocabulário das ciências sociais (e humanas) para se referir a um modelo construído. Podem-se prever novos paradigmas "inventados" ou um paradigma alternativo "emergente" 10 . A ideia de uma mudança de paradigmas é uma metáfora popular para expressar 0

\footnotetext{
8 Langland e Gove não citam Kuhn, apesar de sua terminologia fortemente sugerir que estão familiarizados com seu trabalho.

${ }^{9}$ Ver Longino \& Doell (1983); Haraway (1981).

${ }^{10}$ Ver Janeway (1980) e Person (1980).
} 
desafio e o contradesafio que se percebe na relação entre os estudos feministas e as disciplinas estabelecidas. A visão radical aceita é a de que as pessoas irão defender seus paradigmas atuais porque é pouco confortável ou é ameaçador renunciar ao que se tem. Em seu survey sobre estudos da mulher, Marylin Boxer (1982, p. 258) observa que:

Assim como muitas feministas acharam que o objetivo dos movimentos de mulheres não poderia ser cumprido pelo "método de agregar mulheres e misturá-las", as pesquisadoras sobre estudos da mulher descobriram que os campos acadêmicos não poderiam ser curados do sexismo simplesmente por agregação.

A investigação inicial compensatória se deu conta de que uma reconstrução radical, somente, não seria suficiente. Muitos estudiosos encontraram uma explicação nas teorias sobre revoluções científicas de Kuhn. As formulações de Kuhn foram tomadas como aplicáveis tanto para as ciências naturais, para as quais foram desenvolvidas, quanto para as ciências sociais. Sugiro que elas são menos aplicáveis do que parecem à primeira vista.

Dou um exemplo. Elizabeth Janeway (1980) seguiu as formulações de Kuhn em detalhe para mostrar que elas fornecem uma analogia poderosa para a investigação dos estereótipos sexuais. Kuhn define um paradigma como um corpo no qual estão subentendidas teorias entrelaçadas e crenças metodológicas que permitem a seleção, avaliação e crítica. A mudança é primeiramente avaliada e então registrada como uma anomalia - a pressão das anomalias finalmente força a novos modelos normativos. Janeway argumenta que as representações masculinas acerca da sexualidade feminina proporcionam padrões que se encaixam na estrutura de comportamento aceitável, crenças que proporcionam uma fonte de metáforas admissíveis através das quais as pessoas pensam sobre si mesmas, padrões de comportamento, e exemplos aprendidos da pressão anônima da mitologia social adscritiva. As crenças sobre a sexualidade feminina também atuam como paradigmas kuhnianos em resposta às anomalias. Ao longo do tempo, as anomalias forçam os paradigmas a seguir diferentes posições, ao invés de serem dados como evidentes, transformam-se em ideais a serem divulgadas. Na verdade, Janeway quer insistir no fato de que, para alguns, os ideais masculinos nunca encaixaram. As mulheres poderiam não os compartilhar plenamente, porque não podem encaixar a si mesmas nas expectativas de normalidade masculinas. Os paradigmas, em sua visão, estabelecem as regras da normalidade. 
Todavia, o que fazemos com as contradições internas que os "paradigmas" de Janeway também parecem implicar? A mesma construção de normalidade junto a eixos exclusivamente masculinos, por exemplo, sugerem perguntas sobre o lugar dos homens e das mulheres em relação às suas definições sobre o que é normal. Janeway escreve que "as crenças compartilhadas e os valores expressos por nossos 'paradigmas' de sexualidade feminina não são, de fato, plenamente compartilhados por mulheres que têm que tomá-los como modelos" (JANEWAY, 1980, p. 575). Gostaria de sugerir que o fato de não serem compartilhados se deve menos a uma falha de um paradigma para se ajustar à realidade, do que à estrutura de uma ideologia que, falando em nome de certos interesses sociais, também reproduz outros e, deste modo, promove proposições contraditórias. É importante, então, olhar a maneira pela qual os assim chamados paradigmas são compartilhados.

Sandra Coyner recomenda às/aos praticantes dos estudos das mulheres "que abandonem o gasto de energia e o esforço pouco exitoso para transformar as disciplinas estabelecidas. Ao invés disso, deveriam continuar desenvolvendo a nova comunidade de pesquisadoras feministas que irão descobrir eventualmente novos paradigmas e acharão uma nova ciência normativa" (apud BOXER, 1982, p. 260). Esta interessante afirmação quebra com as suposições de que paradigmas são como um conjunto de normas culturais. Ao invés disso, localizam-nos em relação à comunidade de praticantes. A questão é se nós ainda estamos lidando com paradigmas ou não.

0 próprio Kuhn alega que suas investigações nas ciências naturais se originaram de sua tomada de consciência do grau em que as ciências sociais, ao contrário das primeiras, foram caracterizadas por discordâncias manifestas. Ele confessa estar perplexo pela forma com que sua noção de paradigma tinha sido adotada em outros campos ${ }^{11}$. Kuhn aponta a natureza específica da comunidade das ciências naturais: há relativamente poucas escolas em competição, de modo que revoluções abalam as percepções universais; a comunidade de membros são os únicos que se julgam uns aos outros, e a solução dos problemas é o fim em si mesmo. Kuhn enfatiza os significados compartilhados dos paradigmas, os quais tanto definem uma comunidade científica, quanto são definidos por ela. Por certo, as comunidades científicas existem em diferentes níveis, mas, em geral, haverá um acordo sobre o estatuto do desacordo. Acima de tudo, há um acordo geral

${ }^{11}$ Kuhn (1970), sobre o primeiro ponto, p. viii, sobre o segundo, p. 208. 
sobre a relação dos cientistas com seus objetos: o mundo se apresenta a eles com problemas a serem resolvidos.

Estas são as características de um sistema fechado. A revolução serve somente para fechar mais uma vez o sistema: paradigmas sucessivos são repostos e substituídos uns por outros. A competição aberta entre paradigmas tem vida curta porque os proponentes dos novos paradigmas alegam que eles resolveram os problemas que colocavam o anterior em crise. Contudo, isto dificilmente se encaixa no caso dos estudos feministas, na medida em que há um interesse em que sejam mantidos antagonismos entre paradigmas. Aqui está o grande triunfo do novo "paradigma" que torna o anterior problemático. Na verdade, é um interesse manifesto das feministas terem uma visão conflitiva de seu contexto social. Se assim for, seus marcos conceituais não podem ser considerados como paradigmas.

\section{AS PREMISSAS COMPETITIVAS}

Falar sobre paradigmas não é a mesma coisa que usá-los. A metáfora sugere a imobilidade dos fundamentos e o esforço hercúleo que seria necessário para desarticulá-los. Contudo, quando estamos lidando com cientistas sociais que constantemente derrubam suas próprias teorias e constroem trajetórias explícitas de revoluções internas, não penso que a chave para a resistência seja os desafios feministas aos marcos intelectuais, deixando de lado os "paradigmas". Gostaria de dar conta do incômodo existente na relação entre o feminismo e a antropologia, e da resistência contínua, em diversos níveis, que os estudos feministas encontram. Falar sobre "paradigmas" é parte de um esforço consciente para estabelecer um novo objeto de estudo. 0 que pode não ser tão conscientemente alterado, irei argumentar, é a natureza da relação dos(as) pesquisadores(as) com seu objeto de pesquisa que as práticas investigativas particulares criam. Devemos procurar a constituição social das práticas feminista e antropológica.

Nem os estudos feministas, nem a antropologia social são fechados no sentido kuhniano. Assim, não há uma antropologia; seus(suas) praticantes vão de deterministas a relativistas, desde aqueles(as) interessados(as) nas relações de poder àqueles(as) que priorizam os modelos culturais, de economistas políticos a hermeneutas. Muitas dessas posições correspondem a posições filosóficas ou têm contrapartidas na história ou na crítica literária. Ainda que antropólogos(as) possam se autodenominar pós-estruturalistas, eles(as) não podem se esquivar mais das tradições da literatura contemporânea, como tampouco daqueles que alegam 0 
monopólio sobre o conceito de estruturalismo. Não será surpreendente, então, que, pequeno como é, o campo da antropologia feminista esteja baseado em divisões. Os estudos de antropologia social das mulheres se dividem persistentemente em dois campos relacionados ao entendimento de se a assimetria sexual é ou não é universal. Um lado argumenta que as construções ocidentais não nos permitem enxergar o igualitarismo em contextos pouco familiares e que nós encontramos relações hierárquicas somente no contexto histórico da propriedade privada. 0 outro lado argumenta que deveríamos procurar a desigualdade sexual em todas as suas formas, porque a diferença sexual contribui, por toda a parte, às diferenças socialmente constituídas. Diane Bell (1984) chamou a esses posicionamentos de "evolucionistas" e "universalistas"; eles registram estratégias estabelecidas do manejo antropológico dos dados interculturais.

Qualquer um que revise a teoria feminista terá também que encaixála em suas posições explícitas e autodiferenciadas. Os rótulos têm um sabor político: liberal/radical/socialista-marxista. Os pontos de vista políticos fornecem um modelo para a diferenciação dos pontos de vista feministas, que novamente reproduzem divisões intelectuais latentes no interior da sociedade ocidental em geral. Na verdade, pode-se ver como se houvesse uma multiplicidade impossível de posições teóricas no interior do debate feminista: "Aqui há muitas vozes falando" (HARAWAY, 1981, p. 481) ${ }^{12}$. Contudo, é um prodígio do feminismo que as posições sejam mantidas explicitamente umas em relação às outras. Por meio de uma vasta crítica e contracrítica interna, as vozes dependem da presença uma das outras. Nem é preciso exemplificar o fato de que o feminismo socialista-marxista se define sempre, ele mesmo, em relação ao feminismo liberal e ao radical, sendo isto constantemente lembrado. Os argumentos nunca são esgotados. Em outras palavras, nenhum dos pontos de vista se auto-reproduzem: a "teoria" feminista é criada dialogicamente, no sentido de que todas as posições no debate constituem a sua base. 0 pluralismo que caracteriza ambos os estudos, feministas e antropológicos, parece tê-los tocado fundo em vários pontos. E, aqui, reside 0 contraste com as ciências naturais: não é simplesmente pelo fato de que no interior de cada prática acadêmica se encontram diversas "escolas" (o que também seria verdade para as ciências), e sim porque suas premissas são, por sua natureza, construídas competitivamente em relação a outras.

${ }^{12}$ Ver também Berrett (1980), Eisentein (1984), Elshtain (1981), Sayers (1982). 
Kuhn caracterizou a relação da produção científica com seus objetos de pesquisa como uma relação que se propõe a solucionar problemas. 0 mundo natural é concebido como se fosse composto de coisas diferentes, relacionadas, em última instância, por um conjunto de leis que, por "lógica natural"13, não podem entrar em conflito. 0 problema é como especificar estas leis. Os paradigmas fornecem regras para o registro da natureza dos problemas e de suas possíveis soluções. Nas ciências sociais, entretanto, as diferenças entre as posições teóricas das que eu venho falando correspondem à formação de diferentes interesses sociais. 0 mundo social é concebido como se fosse composto de pessoas que são basicamente semelhantes, porém divididas entre elas mesmas por interesses que geram, de fato, conflitos; mais do que isso, a "lógica social" permite pontos de vista contraditórios. A prática investigativa, que diz respeito à constituição deste mundo social, reproduz internamente esta diferenciação. Seria inútil procurar uma homogeneização ou reconciliação de todos os pontos de vista; [pois] não pode haver, nesse sentido, uma visão de mundo comum. Antes disso, o que constitui o mundo social é a natureza das relações entre diferentes visões definidas por diferentes posições sociais.

O(a) antropólogo(a) não deseja assimilar o caráter de outro sistema ao seu próprio. A essência do método comparativo é dar sentido às diferenças, não anulálas. A teoria feminista também tem um interesse na diferença - nos faz recordar, permanentemente, a "diferença que existe" em considerar as coisas desde uma perspectiva que inclua os interesses das mulheres. Na medida em que interesses de homens e mulheres são opostos, esforços perpétuos devem ser feitos para chamar a atenção a este ponto. Novamente, a homogeneização não faz sentido. As preocupações feministas e antropológicas em promover a diferença parecem ser um motivo a mais para uma convergência mútua. Então, por que a resistência?

A resposta não pode residir em "paradigmas". Primeiro, porque as diferentes posições teóricas ocupadas nas ciências sociais não são análogas aos paradigmas da ciência kuhniana. Elas estão baseadas em conflitos abertos entre estruturas conceituais competitivas que não pode ser reduzidas a uma única posição e, em segundo lugar, porque posições teóricas, em antropologia pelo menos, são, de fato, subvertidas e substituídas muito facilmente - os radicalismos abundam. Poder-seia objetar que tais posições não têm, de fato, status paradigmático, e que deveríamos procurar por paradigmas mais profundos. Todavia, fazer tal coisa poderia ser

${ }^{13}$ Comparar com Evens (1983). 
fácil desde dentro da antropologia: por exemplo, seus encontros com sistemas culturais e sociais alheios permitem examinar a dicotomia sujeito/objeto ou a comodidade de noções que dão forma aos conceitos ocidentais acerca da noção de pessoa e de identidade. Conforme o ponto de vista antropológico, grande parte do pensamento feminista participa de tais construções, as quais contêm explicações etnocêntricas sobre o mundo. Em terceiro lugar, a difícil relação entre o feminismo e a antropologia é vivenciada de forma dramática nas tensões experimentadas por quem se dedica à pratica da antropologia feminista. Estas pessoas estão capturadas entre as estruturas: o(a) estudioso(a) se confronta com duas maneiras distintas para se relacionar com seus objetos de pesquisa. A tensão deve ter continuidade; não pode haver nenhum alívio em substituir uma pela outra.

\section{VIZINHOS EM TENSÃO}

Para expressar a tensão entre a produção feminista e a antropologia, utilizei o termo "incômodo", mais para sugerir hesitação diante do umbral, do que barricadas . Em certo sentido, cada uma zomba da outra porque cada uma quase atinge o que a outra pretende ou visualiza como relação ideal com o mundo.

$\mathrm{Na}$ pesquisa antropológica, há uma longa tradição de ruptura com 0 passado, de maneira que as gerações teóricas tendem a ter vida curta. Um recente herdeiro desta radicalização constante são as inovações interessantes no presente contexto, devido ao peso colocado na interpretação da experiência. A experiência é também um tópico específico das investigações feministas. A visão radical tão argumentada é que a teoria feminista é "experiencial" (KEOHANE et al., 1982, p. VII $)^{14}$, no sentido de que seu primeiro passo é o surgimento da consciência. Em uma forma transmutada, um número de antropólogas feministas enfatiza 0 significado da experiência. Rayna Rapp relata na sua revisão da antropologia de 1979 a "busca por análises mais finamente delineadas da experiência feminina". Mais tarde, ela observa interesses no "corpo vivido" - conceitos próprios das mulheres mediados pela percepção de seus corpos (RAPP, 1979, p. 500-503). Nancy Scheper-Hughes aborda uma antropologia feminista que explora "a natureza do

\footnotetext{
${ }^{14}$ Ver também Register (1980, p. 269). Stacey e Thorne (1985, p. 309) apontam que as teóricas feministas "estão reconsiderando a relação entre o conhecedor e o conhecido para desenvolver um método de investigação que preservará a presença do sujeito como ator e como sujeito da experiência" e enfatizam sua afinidade com outros que contribuem à crítica hermenêutica e neomarxista da ciência social positivista.
} 
eu" em situações de trabalho de campo: a etnografia como uma "autobiografia intelectual" (SCHEPER-HUGHES, 1983, p, 115). Todavia, o enfoque sobre questões semelhantes na escrita etnográfica, em geral, avançou como um desenvolvimento radical bem independente, sem levar em conta a contribuição feminista. 0 objetivo do(as) antropólogos(as) é compreender a "experiência vivida" por meio das percepções do corpo (JACKSON, 1983); "uma nova antropologia da experiência ritual" é anunciada na coleção de ensaios sobre ritos de iniciação (HERDT, 1982, p. XIX). 0 interesse feminista nesses assuntos pode não ser o de desafiar paradigmas que ainda não estão sob desafio dentro da antropologia. Penso de tal forma porque a "experiência" não é o ponto de encontro que parece ser, e minha abordagem sobre isso estará na dificuldade da relação entre a antropologia e os estudos feministas enquanto tais. Contrastarei brevemente o modo como a ideia de experiência é usada no discurso feminista não-antropológico e no discurso antropológico não-feminista. Em cada caso se desenvolve como uma arma contra a ortodoxia.

Os estudos feministas vêem a si mesmos como desafiando os estereótipos que mal representam as experiências das mulheres. As experiências das mulheres podem ser contrapostas à ideologia masculina, incluindo a construção acadêmica da teoria, que se apropria da fala e da imagem em função dos interesses do patriarcado. Estas são as imagens de sexualidade das quais falou Janeway - a mulher é feita para se sentir a si mesma de determinadas maneiras, como se 0 pensamento pudesse ser feito por elas. Muito vinculada ao caráter pessoal, a experiência só pode repercutir nas condições tais como elas são, ainda que 0 significado deva ser trazido à consciência individual. Assim, a experiência se torna no instrumento de um conhecimento que não pode ser apropriado pelos Outros. Somente pode ser compartilhado com pessoas semelhantes.

Essencial a esta visão da tarefa feminista é a necessidade de expor e, por meio disso, destruir a autoridade de outras pessoas para determinar a experiência feminina. A redescoberta constante de que as mulheres são o Outro na consideração dos homens, relembra às mulheres de que elas devem ver os homens como 0 Outro em relação a si mesmas. Criar um espaço para a mulher se converteu em um espaço para o eu, e a experiência se converteu em um instrumento para 0 conhecimento do eu. Então, para a construção de um eu feminista, é necessário 
o Outro não-feminista ${ }^{15}$. 0 Outro é geralmente concebido como o "patriarcado" e as instituições e as pessoas que representam a dominação masculina são simplesmente, de maneira frequente, concretizadas pelo termo "homens". Dado que o objetivo é restaurar à subjetividade um eu dominado pelo Outro, não podem haver experiências compartilhadas com pessoas que permanecem com o Outro.

No interior da antropologia, o foco do(a) etnógrafo(a) sobre a experiência assinala um esforço de se manterem abertos(as) à vida emocional e particular das pessoas. 0 problema é que ao escrever os seus relatos, o(a) etnógrafo(a) deve primeiro traduzir a experiência alheia através de seu(sua) própria experiência e, então, exprimi-la na palavra escrita. Os experimentos contemporâneos com biografias, narrativas e romances constituem uma resposta explícita a este fato (JACKSON, 1982; YOUNG, 1983). A experimentação inclui recentes tentativas autoconscientes de deixar os sujeitos de estudo dos(as) antropólogos(as) falarem por si mesmos. Como historiador da antropologia, James Clifford descreve um novo gênero de trabalhos destinados a reproduzir uma autoria múltipla. Paul Rabinow (1983, p. 196) tipifica o gênero como pós-estruturalista, uma "intercalação de gêneros de texto e vozes misturados" ${ }^{16}$. Ao permitir que os chamados informantes falem com sua própria voz, a etnografia resultante reproduz o processo interlocutório do trabalho de campo, o qual sempre repousa na colaboração entre antropólogo(a) e informante. Os(as) antropólogos(as) e suas reações são, então, parte dos dados, ao invés de serem mãos escondidas e misteriosas. As próprias experiências dos(as) antropólogos(as) são as lentes por meio das quais outras pessoas de sua própria sociedade podem alcançar tal compreensão. Estas experiências se tornam, consequentemente, um veículo para explicações ou relatos interculturais, tal como quando as reações pessoais de Rabinow no campo revelam um "eu cultural"17.

A antropologia, aqui, constitui-se a si mesma em relação com um "Outro", em um vis-à-vis com a cultura/sociedade estranha sob estudo. Sua distância e estranhamento são deliberadamente mantidos. Mas o "Outro" não está sob ataque. Pelo contrário, o esforço consiste em criar a relação com o Outro, como uma busca de um meio de expressão que ofereça interpretações mútuas, talvez

\footnotetext{
${ }^{15}$ Ver Haraway (1981); e Lloyod (1984, p. 14). Entretanto, Keohane et al. (1982) delimitam as variedades de consciência, das quais a consciência de si mesmo como objeto da atenção de outro é somente uma entre outras.

${ }^{16}$ Ver também Clifford (1983).

${ }^{17}$ Ver, por exemplo, Rabinow (1977).
} 
visualizadas como um texto em comum, ou um diálogo. Clifford desenvolve o conceito de "discurso" para evocar a estrutura de um diálogo que preserve as múltiplas e distintas vozes de seus autores, e que ainda forneça um produto que todos eles compartilham em alguma medida. Sob ataque, pelo contrário, está a parte de si mesmo(a) incorporada na tradição da qual se é herdeiro . Alega-se que as pretensões da velha antropologia obliteram a autoria múltipla dos dados do trabalho de campo e que não reconhece o imput tanto do informante como da experiência particular dos(as) antropólogos(as).

A investigação feminista sugere que é possível descobrir o eu ao se tornar consciente da opressão proveniente do "Outro". Deste modo, pode-se tentar recuperar um passado comum queé também o passado de si mesmo. A investigação antropológica sugere que o eu pode ser conscientemente usado como um veículo para representar a um Outro. Mas isto é somente possível se o eu rompe com seu próprio passado. Assim, então, emergem como dois radicalismos muito diferentes. Devido a seus interesses paralelos, as duas práticas são diferentemente estruturadas na maneira em que organizam o conhecimento e traçam fronteiras, em suma, em termos de relações sociais que definem suas comunidades de pesquisadores(as).

Talvez as diferenças poder-se-iam converter em um diálogo entre os estudos feminista e a antropologia. Mas seria um diálogo incômodo na medida em que cada um tem um potencial para minar o outro, visto que ambos são vulneráveis à base ética que consideram tão importante. Construo um encontro hipotético para realçar este ponto.

\section{ESCÁRNIO ENTRE VIZINHOS}

Como pode ser dito que o feminismo ironiza este modelo de antropologia? 0 (a) antropólogo(a) tenta se estabelecer como um intérprete de experiências. Contudo, o(a) antropólogo(a) obviamente admitiria estar no controle do texto final. Não obstante a maior parte de a autoria múltipla ser reconhecida, usar as experiências das pessoas para fazer afirmações sobre matérias de interesse antropológico acaba por subordinar estes textos aos usos da disciplina. Mas isto não significa que este seja um exercício sem valor. Pelo contrário, e pelo fato da questão da ética ser colocada em relevo, o argumento de a autoria múltipla ser 
desejável exprime a relação ideal com os(as) informantes. 0(a) etnógrafo(a) está ansioso(a) não somente para dar a conhecer a experiência dos outros em seus próprios termos, mas para preservar sua dignidade separada. Apresentar uma monografia como uma produção em colaboração é, assim, uma metáfora da situação ética ideal na qual nenhuma voz é subsumida pelo 0utro ${ }^{18}$.

Conforme a perspectiva feminista, por certo, pode não haver colaboração com o Outro. 0 ideal antropológico é uma ilusão, dada a dimensão crucial dos diferentes interesses sociais. Não pode existir paridade entre as autorias do(a) antropólogo(a) e do(a) informante; o diálogo sempre será assimétrico. Os mundos sociais de antropólogos(as) e informantes são diferentes, seja por conta de que os fatores primários da relação são as relações coloniais entre as sociedades das quais antropólogos(as) e informantes são oriundos, ou seja pelo fim que será dado ao texto. Eles não têm interesses em comum aos quais possa servir este produto supostamente comum.

Ainda que eu tenha usado o caso da inovadora etnografia da experiência, a etnografia em geral se baseia em valores amplamente difundidos no interior da disciplina. A prática antropológica poderia cessar se não pudesse implementar, de alguma forma, uma ética de trabalho humanista (BELLAH, 1977, p. XII). A crítica feminista parte de diferentes premissas, mas isso não impede o seu escárnio às pretensões antropológicas em seu lado mais vulnerável. Na verdade, o escárnio vem sempre de um ponto de vista diferente, de tal maneira que o golpe bate enfurecidamente pela tangente. Mas as feministas estão próximas de mostrar uma rota alternativa à expectativa dos(as) antropólogos(as) de realizar pesquisas em colaboração. Os estudos feministas podem alegar interesses substanciais em comum com as pessoas que estudam. Elas podem estar falando de mulher para mulher, ou então ter uma base comum na compreensão dos sistemas de dominação.

Como pode, então, a antropologia zombar do feminismo? A abordagem do feminismo radical enfatiza a criação consciente do eu ao ver suas diferenças com 0 Outro. As mulheres precisam saber a dimensão na qual suas vidas estão moldadas por valores patriarcais. Perceber este abismo é uma conquista e, por sua vez, uma posição ética, o que valida o compromisso das mulheres entre si. Agora, se tal

\footnotetext{
${ }^{18}$ Rabinow (1977, p. 204) sugere que isto não é a autenticidade que os textos de Leenhardt em co-autoria alegam, mas é "um produto eticamente superior de trabalho em conjunto" (itálicos meus). Ver Clifford (1980) e Young (1983).
} 
feminismo zomba das pretensões antropológicas em criar um produto que seja, de alguma forma, de autoria conjunta, então a antropologia zomba da pretensão de que as feministas podem realmente alcançar esta separação de um Outro antiético que desejam. De um ponto de vista externo a sua própria cultura, os antropólogos vêem que muitas bases de separação repousam em suposições culturais comuns sobre a natureza da noção de pessoa [personhood] e de suas relações. Se as mulheres constroem a subjetividade por elas mesmas, então o fazem estritamente dentro das restrições socioculturais de sua própria sociedade. A fundação do eu deve endossar uma cosmovisão compartilhada de forma equânime com os Outros.

Novamente, isto constitui questões éticas sobre as quais as pensadoras feministas se preocupam: um discurso silencioso, a conivência e a participação na opressão; e como criar um discurso feminista que rechace a dominação na medida em que a própria linguagem é concebida como um instrumento de dominaçãa ${ }^{19}$. 0 feminismo requer um dogma de separatismo como instrumento político para constituir uma causa comum. Os(as) antropólogos(as) zombam das feministas quando eles(as), quase sem esforço, conseguem se distanciar de sua própria sociedade, distancia que às feministas custa tanta angústia. Todavia, mais uma vez, o escárnio também se desvia, porque, de fato, as feministas habitam a sua própria sociedade e é irrelevante a descoberta de que seus valores estão limitados culturalmente. As feministas podem apenas operacionalizar suas perspectivas se estas forem tomadas como tendo congruência com a realidade. Assim, elas não precisam saber que não podem "realmente" se distinguir de um Outro opressor; pelo contrário, o que elas precisam saber são as formas pelas quais elas "realmente" podem e devem fazê-lo..

Se buscarmos nas ciências sociais ideias comparáveis ao status que os paradigmas têm nas ciências naturais, pode ser de grande valia recordar que os paradigmas na definição de Kuhn são visões de mundo compartilhadas que vêm do fazer científico, e não do fato de adquirir regras para fazê-las.

Nas ciências naturais, tais visões de mundo tomam, necessariamente, a forma de paradigmas intelectuais, isto é, modelos para organizar o conhecimento sobre o mundo. Sugeri que as teorizações conscientes sobre o conhecimento que caracterizam ambos os pensamentos, feminista e antropológico, não são melhores conceitualizados em termos de paradigmas. Contudo, há um conjunto de visões, análogo aos paradigmas, que é considerado, de forma idêntica, tão fundamental

${ }^{19}$ Ver Elshtain (1982, p. 145). 
por feministas e antropólogos que nenhum dos dois poderia proceder sem ele. Mas estas visões não podem ser abertas ao desafio consciente, porque definem a prática por meio da qual atuam. Elas, assim, não aparecem como "visões" de qualquer modo, mas como conhecimento do mundo. É um mundo social e envolve as diferentes relações que feministas e antropólogos(as) construíram com respeito ao Outro.

Emboraeu tenhameestendido sobre abordagens particulares, as construções do Outro, brevemente descritas aqui, podem ser generalizadas para o feminismo e para a antropologia como um todo. Estas construções são fundamentais. Quando são trazidas à tona e comparadas, seus proponentes não podem se desafiar, porque uma não é substituta da outra. Conforme escreve Kuhn, sobre os proponentes de paradigmas científicos em competição, eles praticam seus intercâmbios em mundos diferentes. Na verdade, o status propriamente paradigmático destas duas práticas é revelado na medida em que elas aparecem irrelevantes uma à outra e, então, não oferecem um desafio, mas sim o que eu chamei de escárnio.

\section{REFERÊNCIAS}

ARDENER, Edwin. Belief and the problem of women. In: LA FONTAINE, Jean (ed.). The interpretation of ritual. London: Tavistock Publications, 1972.

ATKINSON, Jane Monning. Anthropology (Review essays). Signs 8, Chicago, n.2, 1982, pp.236-58.

BARRETT, Michèle. Women's oppression today: problems in Marxist feminist analysis. London: Verso, 1980.

BELL, Daine. Daughters of the dreaming. Melbourne: McPhee Gribble/George Allen \& Unwin, 1984.

BELLAH, Robert. Foreword. In: RABINOW, Paul. Reflections on fieldwork in Marrocos. Berkeley: University of California Press, 1977.

BOXER, Marilyn. For and about women: the theory and practice of women's studies in the United States. In: KEOHANE, Nannerl; ROSALDO, Michelle; GELPI, Bárbara (ed.). Feminist theory: a critique of ideology. Sussex: Harvester Press, 1982.

CLIFFORD, James. On ethnographic authority. Representations, Berkeley, n.1, 1983, pp.118-46. 
Fieldwork, reciprocity and the making of ethnography texts: the example of Maurice Leenhardt. Man, Londres, n. 15, 1980, pp.518-32.

EISENSTEIN, Hester. Contemporary feminist thought. Sidney: Unwin Paperbacks, 1984.

ELSHTAIN, Jean Bethke. "Feminist discourse and its discontents: language, power and meaning. In: KEOHANE, Nannerl; ROSALDO, Michelle; GELPI, Bárbara (ed.). Feminist theory: a critique of ideology. Sussex: Harvester Press, 1982.

Public man, private woman: woman in social and political thought. Princeton, N.J.: Princeton University Press, 1981.

EVENS, T.M.S. Mind, logic and the efficacy of the Nuer incest prohibition. Man, Londres, n. 18, 1983, pp.11-33.

HARAWAY, Donna. In the beginning was the world: The Genesis of Biological Theory. Signs 6, Chicago, n. 3, 1981, 469-81.

HERDT, Gilbert. Preface to Rituals of manhood: male initiation in Papua New Guinea. Berkeley/Los Angeles: University of California Press, 1982.

JACKSON, Michael. Knowledge of the body. Man, Londres, n.18, 1983, pp.327-45. . Allegories of the wilderness: ethics and ambiguity in Kuranko narratives. Bloomington: Indiana University Press, 1982.

JANEWAY, Elizabeth. Who is Sylvia? On the loss of sexual paradigms. Signs 5 , Chicago, n. 4, 1980, pp.573-89.

KEOHANE, Nannerl; ROSALDO, Michelle; GELPI, Bárbara (ed.). Feminist theory: a critique of ideology. Sussex: Harvester Press, 1982.

KUHN, Thomas. The structure of scientific revolutions. Chicago: University of Chicago Press, 1970. [A estrutura das revoluções científicas, São Paulo: Perspectiva, 2006].

LANGLAND, Elizabeth; GOVE, Walter. A feminist perspective in the academy: the diference it makes. Chicago: University of Chicago Press, 1983. Publicado primeiramente pela Society for Values in Higher Education and Vanderbilt University, 1981

LLOYD, Genevieve. History of philosophy and the critique of reason. Critical Philosophy, n. 1, 1984, pp.5-23. 
LONGINO, Helen; DOELL, Ruth. Body, bias and behavior: a comparative analysis of reasoning in two areas of biological science. Signs 9, Chicago, n.2, 1983, pp.20627.

MACCORMACK, Carol. Anthropology - a discipline with a legacy. In: SPENDER, Dale (ed.). Men's studies modified. New York: Pergamon Press, 1981.

PERSON, Ethel Spector. Sexuality as the mainstay of identity: Psychoanalytic perspectives. Signs 5, Chicago, n. 4, 1980, pp.605-30.

RABINOW, Paul. "Facts are a word of God": an essay review of James Clifford's Person and myth: Maurice Leenhardt in the Melanesian world". In: STOCKING, G. (ed.). Observers observed: history of anthropology. Madison: University of Wisconsin Press, 1983.

. Reflections on fieldwork in Marrocos. Berkeley: University of California Press, 1977.

RAPP, Rayna. Anthropology (Review essay). Signs 4, Chicago, n. 3, 1979, pp.497513 .

REGISTER, Cheri. Literary criticism (Review essay). Signs 6, Chicago, n. 2, 1980, pp.268-82.

SAYERS, Janet. Biological politics: feminist and anti-feminist perspectives. London: Tavistock Publications, 1982.

SCHEPER-HUGHES, Nancy. Introduction: the problem of bias androcentric and feminist anthropology. Women's studies, n. 10, 1983.

SHAPIR0, Judith. Anthropology and the study of gender. In: LANGLAND, Elizabeth; GOVE, Walter. A feminist perspective in the academy: the diference it makes. Chicago: University of Chicago Press, 1983.

. Cross-cultural perspectives on sexual differentiation. In: KATCHADOURIAN, H. (ed.). Human sexuality: a comparative and developmental perspectives. Berkeley/Los Angeles: University of California Press, 1979.

STACEY, Judith; THORNE, Barrie. The missing feminist revolution in sociology. Social Problems 32, Berkley, n. 4, 1985.

YOUNG, M. Magicians of Manumanua: living myth in Kalauna. Berkeley/Los Angeles: University of California Press, 1983. 